\title{
Tax amnesty and secondary tax evasion
}

\author{
YU-KUN WANG* (1), LI ZHANG and WE-ME HO
}

Department of Economics and Finance, Guangdong Ocean University Cunjin College, PR China

Received: May 8,2019 • Revised manuscript received: August 26, 2019 • Accepted: September 10, 2019

(c) 2020 Akadémiai Kiadó, Budapest

\begin{abstract}
Though tax amnesties (TAs) are considered as a policy tool to increase revenue for governments, they have generated some puzzles. To solve the puzzles of TA we should not ignore the behavioural aspects of delinquent taxpayers. In this paper, we focus on a relatively neglected but important area of the TA literature. Considering that people who participate in tax amnesty policy (TAP) may not honestly report the whole amounts of evaded tax, thus they commit a secondary tax evasion. We indicate that even considering the risk of abstaining from TA and incurring possible uncertainty of tax evasion penalties, participating in a TA provides a higher level of utility for the delinquent taxpayers. Also, due to a secondary tax evasion usually accompanying with TA, we show that during the initial assessment period of a TAP the tax revenue drastically increases and when the assessment period is approaching the tax revenue stably declines and ultimately converges to a fixed value. Furthermore, we show that if delinquent taxpayers participate in the TAP and the penalties are larger than the expected tax revenue of the government, it increases the tax revenue without reducing the welfare of other taxpayers, so as to achieving Pareto improvement.
\end{abstract}

\section{KEYWORDS}

tax amnesty, hidden cost, secondary tax evasion, puzzle of compliance, Pareto improvement

\section{JEL CLASSIFICATION INDICES}

C41, H26, E62, K04

\footnotetext{
*Corresponding author. E-mail: 3434337238@qq.com
} 


\section{INTRODUCTION}

Almost all the US states have offered TAPs since 1980. Just recently, Illinois has enacted a TAP in 2019 that allowed delinquent taxpayers to automatically participate in a one-and-a-halfmonth TAP to pay their past tax evasion during the period from June 2011 to July 2018. In 2018, New Jersey has provided a TAP which applies only to the past tax evasion occurred by delinquent taxpayers between 2009 and 2017. According to this, if a taxpayer is eligible but chooses not to use the tax amnesty, an additional fine of $5 \%$ will be imposed on any eligible amount pending during the amnesty period.

In 2012, the Spanish government announced a tax amnesty for undeclared assets or those hidden in tax havens. Repatriation was allowed by paying a 10 per cent tax with no criminal penalty. In 2014, the Liechtenstein government advocated the idea of a one-off, non-punitive voluntary declaration of non-compliance TAPs, a similar program to the one currently enforced in Switzerland to avoid an 'accumulation' of amnesties. It is also worth to note that many developing countries, such as Chile, Colombia, India, and Mexico often repeatedly and incessantly employed TAPs.

Arindam et al. (1995) provide empirical estimates of the revenue impact of Indian income tax amnesties between 1965 and 1993. Their results indicate that only the 1975 amnesty appears to have had a positive impact on tax revenue while other amnesties having either negligible or even negative effects. According to Ueng - Yang (2001), if a tax evader is willing to pay penalties to the government before being caught for a tax evasion, the government will no longer detect the tax evader's previously declared income (which may be unreported). On the other hand, for the government the expense of collecting these delinquent taxes is relatively low.

There is some evidence that countries with successful amnesties show signs of observable improvements in economic conditions right around their amnesty times. For instance, Uchitelle (1989) depicts Ireland (in 1988) that showed steady growth in terms of GDP during the amnesty time. A similar experience holds for the Indian tax amnesties of 1975 and 1997 that are publicly acknowledged as successful cases (Das-Gupta et al. 1995).

Luitel - Sobel 2007 suggested that, in general, if a country declares an amnesty program, it brings the government, at first, temporary revenue augments during the amnesty period, but later, causes a reduction in the revenue. Fisher et al. (1989) and Luitel - Mahar (2013) suggested that tax amnesties raise higher tax revenues for the US state treasury in the short term. However, Laborda - Rodrigo (2003) found that amnesties had no effect on tax revenue neither in the short nor the long term.

Why would a rational individual accept an amnesty and pay past dues? How can the existing literature explain why tax evaders may find it worthwhile to take advantage of the TAPs? Leonard - Zeckhauser (1987) argued in favour of TAPs that some people obtain and no one sacrifices if a TAP is provided. Nevertheless, Olivella (1996) suggested that although governments offer TAPs, delinquent taxpayers may not participate in such programs. As he noted, the delinquent taxpayers join TAPs and honestly pay the evaded taxes, they risk incurring stringent inspections by tax authorities on their previous annual incomes because of the increase in reported income; and this can hamper future intentions to evade paying taxes. Also, Alm et al. (1990) argued that the expectation of an upcoming amnesty significantly reduces compliance, however, these negative impacts on tax compliance can be offset by greater post-amnesty enforcement efforts. Cyert - DeGroot (1987) argued that tax evaders are not well aware of the 
disutility from tax evasion when they file their tax returns but learn it through experience. If they later learn that they would like to be more honest than they have been, an amnesty gives them an opportunity to repay the evaded tax amounts.

In practice, if tax evaders fail to honestly repay the evaded taxes after joining TAPs, when the unreported proportion is subsequently discovered by tax authorities, they must pay penalties equivalent to those paid by the tax evaders who did not join the program when found guilty of tax evasion.

Unfortunately, the existing theories of tax amnesties have neglected the influence of this condition on expected utility, income and risk behaviour of the tax evaders. Our paper considers the influence of tax averters' partial or complete participation in TAPs (where secondary tax evasion potentially occurs) on their income, expected utility, risk appetite and choice behaviours. Furthermore, the impact of perceived tax revenue with tax amnesty is also analysed.

The structure of this paper is as follows: Section 1 provides the introduction. In Section 2, we establish the model and then demonstrate the relationship between delinquent taxpayers and government, and discuss the conditions that must be fulfilled for government tax amnesty plans to succeed. Section 3 analyses delinquent taxpayers, who participate in the tax amnesty plan but repeat tax evasion, that is the so called 'secondary tax evasion under tax amnesty plan', and the effect of participating or not participating in the tax amnesty plan on expected utility and riskrelated decisions. The revenue and Pareto improving implications of tax evaders participating in TAPs are discussed in Section 4 and the last Section 5 concludes.

\section{MODEL}

Consider the following simple case. All individuals have the same income, they are risk neutral, and have the same utility function. In utility models, non-expected utility theories, such as the subjectively weighted utility, the Allais paradox, the prospect theory and the rank-dependent expected utility theory have been used to explain that people's decision-making behaviour is irrational contrary to the expected utility hypothesis. Yet, using the subjective weights or subjectively weighted utilities to analyse the decision-making behaviour of people typically causes the sum of the subjective weights of the tax evaders to be greater than 1 , which contradicts the economic and rational behaviour proposed in the expected utility hypothesis. ${ }^{1}$ Therefore, we adopt the von Neumann-Morgenstern axioms to analyse the occurrence probability of each type of situation to satisfy the hypothesis that economic activities performed collectively by a society are equalized.

Suppose a tax evader makes decisions by envisioning the consequences of his actions, and then, choosing an action that maximizes his/her expected utility. Regardless of whether the tax evasion activities are caught, let a tax evader's fixed real income, $y^{\sigma}$, is given. Reported income is taxed at the marginal tax rate $m . \mathrm{F}(s)$ be the function of the hidden cost of each dollar evaded, and $s$ be the ratio of the hidden cost of each dollar evaded to the evaded one dollar. The hidden

\footnotetext{
${ }^{1}$ Considering the prospect theory, for example, it replaces the probability of the risky occurrence with a "weighting function" that under-weighs the high probabilities and over-weighs the low ones. Therefore, the prospect theory has failed so far to attract the attention of economists as a valuable tool of analysing tax amnesties, an exception being Alm Beck (1990).
} 
cost of each dollar evaded is expressed as $C(s)=s \times \int \mathrm{d} F(s)$, where $F_{s}^{\prime}(s)=f_{s}(s), s \in[0,1]$, $C(0)=C^{\prime}(0)=0, C^{\prime}(s)>0, C^{\prime \prime}(s)>0$, and $y^{\sigma}>0$, denoting the fixed real income of the tax evader, while $\sigma$ is the coefficient governing the relationship between changes in income and changes in tax payments.

Following Slemrod -Yitzhaki (2002), we assume that the government may impose a higher tax rate on those who earn more than a certain amount of income. Let $\sigma=Z^{m} / Z^{m}-\bar{Z}$, where $Z^{m}$ is the income of the high-income people, $\bar{Z}$ is the threshold amount set by the government for imposing higher differential tax rate on a certain income and above. When $\bar{Z}>0, \sigma>1$, the larger $\bar{Z}$ implies the larger $\sigma$, we obtain that the higher the threshold amount for the high-income people is, the larger $\sigma$ will be. When $\bar{Z}=0, \sigma=1$, the government levies the same single proportional tax on low income, middle income and high income.

We assume a tax evader faces two conditions: $p$, the probability of being caught evading taxes; and $(1-p),{ }^{2}$ the probability of a successful escape, assume $p$ is independent of the reported income. Let $v$ be the proportion of unreported income to fixed real income. In this case, suppose that $\tau$ is the penalty rate that must be paid to the government for each dollar evaded by a tax evader who does not join a TAP and is found guilty of tax evasion, ${ }^{3}$ where $\tau(m)>m$. Also, our proposition in line with Torgler - Schaltegger (2005) indicates that a second or third tax amnesty does not improve tax compliance. Hence, we assume that tax amnesty can only be used once. It is also assumed that, if audited, all of the unreported income of a tax evader will be discovered. If a tax evader joins a TAP after evading taxes, the amnesty penalty rate of each dollar evaded is $\chi, \forall \chi<\tau$.

We assume that the delinquent taxpayers' behaviour is affected by whether other people pay taxes honestly or not. For a tax evader, we assume the disutility of evading tax is increasing in the fraction of honest taxpayers, where $h \in[0,1]$ denotes the fraction of honest taxpayers in society. The coefficient $A_{z}$ measures the degree of disutility that a tax evader feels when $100 \mathrm{~h}$ per cent of taxpayers report income honestly, where $A_{z} \in[0,1]$. In case of evasion, let the expected rate of return on a dollar of evaded tax $E(r)=(1-p-\tau \times p) \times m$ be strictly positive (or, $(1-p) / p>\tau)$. Under this assumption, the government may eliminate tax evasion simply by choosing $p$ and $\tau$ so that $E(r) \leq 0$. However, should the government employ $p$ and $\tau$, if it can influence this parameter? This paper accords with the general experience and adopts Andreoni's (1991) suggestions that it may rather be costly for government to do so. Equation (1) represents the premise that a TAP is not joined following a tax evasion:

$$
\begin{aligned}
& (1-p)\left(1-m(1-v)+m r v-A_{Z} h\right)+p(1-m+v m-\tau m v)>1+m \chi v \\
& \quad+s m v \int \mathrm{d} F(s), \forall s, \forall 0 \leq v \leq 1
\end{aligned}
$$

Further, we denote that, when risks are unidentified, the tax evaders encounter two choices after evading taxes: (i) participating in TAPs and paying penalties, or (ii) not joining such program but risking the probability of being caught versus successful escape.

\footnotetext{
${ }^{2} \tau \times p<1$, it denotes that the corner solutions are eliminated and only the interior solutions are considered in this model.

${ }^{3}$ Because part of the unreported incomes may be legally exempted incomes, the method of Yitzhaki (1974) was adopted which implies penalties based on evaded taxes, rather than penalties based on evaded incomes as suggested by Allingham-Sandmo (A-S) model (1972).
} 
Let $\chi$ be the penalty rate of each dollar evaded by the representative tax evader who joins a TAP before being caught of evading taxes in previous years, and $m<1<\chi<\tau$. Let $\kappa$ be the proportion of back duty payments to the actual unreported taxes of a tax evader after joining that TAP, and $\kappa \in[0,1]$. The value of this proportion is only known to the tax evader who voluntarily repays his/her delinquent taxes, where $y$ is the real income of the representative tax evader.

Hence, if a representative taxpayer participates in the tax amnesty plan and voluntarily declares the tax evaded, the negotiated penalty for tax amnesty payable is $\kappa y m v \chi$. This paper stands in contrast with some existing literature. We assume that a tax evader in an amnesty program does not honestly repay the evaded taxes. When the unreported proportion $1-\kappa$ is subsequently discovered by tax authorities, the additional amount of the due penalties can be expressed as $(1-\kappa) y m v \tau$. Let $q$ be a representative tax evader's probability of being found by the government when the evader actively participates in the tax amnesty plan but fails to fully declare the tax evaded and $\theta$ denotes the probability of being caught hiding incomes through any type of government inspection.

Given the definition, an effective tax amnesty strategy provided by the government can be expressed as follows:

Proposition 1. The premise for establishing an effective TAP is $\frac{\varpi^{\circ}}{q_{t}}<\theta_{t}^{*}$.

Proof: See Appendix 1 for details.

\section{THE SECONDARY TAX EVASION UNDER TAX AMNESTY}

Let $\varepsilon$ be the ex-ante probability of a tax evader who joins a TAP after evading taxes, and $1-\varepsilon$ be the probability of not joining such program, where $\varepsilon\left(y^{\sigma} v\right)=\int_{\Omega\left(y^{\sigma} \times v\right)} f(\lambda) d \lambda, \varepsilon \in[0,1]$. We assume that the real income is subject to some shock, $\lambda$, and the shock is supposed to be a stochastic variable with probability distribution function $f(\lambda), \lambda \in(-\infty, \infty)$. To see this, we quote Andreoni's (1991) definition to resolve this exogenous variable, $\varepsilon$. Consider a tax evader initially underreports $y^{\sigma} \times v$, assume that he/she knows $f(\lambda)$ but does not realize $\lambda$. After experiencing $\lambda$, a tax evader is given an opportunity for the amnesty program. Let $\Phi\left(y^{\sigma} v ; \lambda ; s\right)=U\left(y^{e}\right)-U\left(y^{c}\right)-y^{\sigma} m v s \int d F(s)$ be the ex post net utility gain from participating in a tax amnesty. Then a tax evader will take the tax amnesty if and only if $\Phi \geq 0$. In spite of $\lambda$ is exogenous, a tax evader has some control over $\Phi$ through his/her choice of $y^{\sigma} \times v$. Therefore, we define the set function $\Omega\left(y^{\sigma} v\right)=\left\{\lambda: \Phi\left(y^{\sigma} v ; \lambda ; s\right) \geq 0\right\}$. Given $\mathrm{U}(\bullet)$ is a von Neumann-Morgenstern cardinal utility function (1944), and if $\lambda \in \Omega\left(y^{\sigma} v\right)$, a tax evader will take the amnesty. In this scenario, according to Proposition 1, when $\frac{\frac{\pi}{}^{\circ}}{q_{t}}<\theta^{*}$, that is, $\theta^{A} \leq \theta_{t-1}=\theta^{*}, \kappa \notin\left[-\infty, \theta^{A}\right]$, $\forall \varepsilon, 0<\varepsilon \leq 1$, then a tax evader joins a TAP.

Thus, as defined by this paper, a tax evader with a differentiable von Neumann-Morgenstern cardinal utility function will make a choice after evading taxes: either (1) participating in TAPs and paying penalties, or (2) not joining such program but risking the probability of being caught versus successful escape, then, the expected utility of a tax evader can be expressed as:

$$
\hat{\mathrm{Eu}}\left(y^{\sigma}\right) \equiv(1-\varepsilon) \mathrm{U}\left(y^{c}\right)+\varepsilon \mathrm{U}\left(y^{e}\right)-y^{\sigma} m v s \int \mathrm{d} F(s), \quad \forall \varepsilon
$$

Assume that in Eq. (2),

$$
y^{c}=(1-p)(1-m(1-v)+v m r-A h) y^{\sigma}+p(1-m+v m-\tau m v) y^{\sigma}, \text { and }
$$


$y^{e}=y^{\sigma}[1-\chi m v k-m v \tau(1-k) q \theta]$, where $y^{c}$ is the expected revenue for a tax evader not joining TAPs, and $y^{e}$ is the expected revenue for a tax evader joining such programs. Therefore, the joint probability density function can be expressed as $f_{y^{e}}\left(y^{e}\right)=$ $\frac{d}{d y^{e}} \int_{0}^{\infty}\left\{\int_{0}^{1} f_{y^{e}, \varepsilon}\left(y^{e^{\prime}}, \varepsilon^{\prime}\right) \mathrm{d} \varepsilon^{\prime}\right\} \mathrm{d} y^{e^{\prime}}=\int_{0}^{1} f_{y^{e}, \varepsilon}\left(y^{e}, \varepsilon^{\prime}\right) \mathrm{d} \varepsilon^{\prime}$, and as a taxpayer decides to evade taxes. As mentioned earlier, let $v$ be the proportion of hidden incomes to actual incomes (i.e. the rate of tax erosion)., then, the Hamiltonian first-order optimal control condition of $v$ for the expected utility of tax evasion implies:

$$
\begin{aligned}
H= & {\left[(1-\varepsilon) p y^{\sigma} m(\tau-1)-(1-\varepsilon)(1-p) m(1+r) y^{\sigma}\right] U^{\prime}\left(y^{c}\right) } \\
& +\left[\varepsilon y^{\sigma} \chi m \kappa+\varepsilon y^{\sigma} m q \tau \theta(1-\kappa)\right] U^{\prime}\left(y^{e}\right)+y^{\sigma} m s \int \mathrm{d} F(s)=0,
\end{aligned}
$$

The requirement for internal solution is $\tau<\frac{(1-p)(1+r)+p}{p}, \forall \varepsilon$. Equation (4) indicates that the second order condition of $v$ for the expected utility is $H_{v}<0$, or, $\partial^{2} H / \partial v^{2}<0$. This reveals that the utility function of a tax evasion is strictly concave, $U^{\prime \prime}(\dot{s})<0$, and therefore, the representative tax evader is a risk averse. ${ }^{4}$

$$
\begin{aligned}
& H_{v}=(1-\varepsilon)\left[p y^{\sigma} m(\tau-1)-(1-p) m(1+r) y^{\sigma}\right]^{2} U^{\prime \prime}\left(y^{c}\right)+\varepsilon \\
& {\left[y^{\sigma} \chi m \kappa+y^{\sigma} q \theta m \tau(1-\kappa)\right]^{2} U^{\prime \prime}\left(y^{e}\right),}
\end{aligned}
$$

As mentioned earlier, $\kappa$ be the proportion of back duty payments to actual unreported taxes of a tax evader after joining that TAP. Using Eq.(3), it is simple to show that the influence of $\kappa$ on the second order condition $H_{K}$ for the expected utility of tax evasion is:

$$
\begin{aligned}
H_{\kappa}= & \varepsilon \times y^{\sigma} \times m \times(\chi-\tau) \times U^{\prime}\left(y^{e}\right)+\left[\varepsilon \times y^{\sigma} \times \chi \times m \times \kappa\right. \\
& \left.+\varepsilon \times y^{\sigma} \times m \times \tau \times(1-\kappa) q \theta\right] \times m \times v \times y^{\sigma} \times(\tau q \theta-\chi) \times U^{\prime \prime}\left(y^{e}\right)
\end{aligned}
$$

Eq. (5) clearly demonstrates that the function of $\kappa$ (i.e. the proportion of back duty payments) to the second order condition for the expected utility of tax evasion can be discussed as follows:

(i) If $\tau q \theta>\chi$, then $H_{K}$ is strictly concave (i.e. $H_{K}<0$ ), which means that the representative tax evader is a risk averse.

(ii) If $\tau q \theta=\chi$, then $H_{K}$ is strictly concave (i.e. $H_{K}<0$ ), which means that the representative tax evader is a risk averse.

(iii) If $\tau q \theta<\chi$, then $H_{K} \geqq 0$ or $H_{K} \leqq 0$, which means that the representative tax evader may evade tax again after participating in the tax amnesty plan.

The above deduction denotes that even the representative tax evader participating in a TAP may not honestly report the whole amounts of evaded tax, thus may commit a secondary tax evasion.

Proposition 2. In the circumstances of a partial or complete participation in a TAP, when the penalty rate is based on the evaded taxes, the second order condition of the hidden-to-actual income proportion, $v$, for the expected utility of tax evasion is $H_{v}<0$, confirming the assumption that Hamiltonian is a strictly concave function for $v$ and that the representative tax evader is a risk-averse. But $H_{K}$ may be greater than zero, $H_{K} \geqq 0$, or less than zero, $H_{K} \leqq 0$, confirming the

\footnotetext{
${ }^{4}$ The second order conditions for the expected utility of tax aversion, $H_{v}<0$ and $H_{\kappa}<0$, indicate that for either the initial or secondary tax evasion after joining a TAP, large amounts of hidden income increase the risk aversion of a tax evader.
} 
assumption that if $\tau q \theta<\chi$, then the representative taxpayer may not fully declare his/her tax evasion after participating in the tax amnesty, resulting in a second tax evasion.

Andreoni (1991) found that the expected utility of tax amnesty for the representative tax evaders after an evasion, the higher the income of tax evaders who hide, the higher their willingness to take part in the tax amnesty plan afterwards, the more risk averse they are. In this paper, we supplement that when $\tau q \theta<\chi$, taxpayers participate in the tax amnesty plan, they may not pay $100 \%$ of the tax they evaded before they joined the tax amnesty plan. According to Proposition 2, it is found that the penalty of taxpayers participating in the tax amnesty scheme should not be too high, otherwise, tax evaders may evade taxes again (Macho-Stadler et al. 1999).

The central question concerns the choice to be made between participating in a TAPs after evading taxes or abstaining from it and incurring possible uncertainty of tax evasion penalties. To discuss this question, this section derives the preference implications of the sign of $U^{\prime \prime}$ and $U^{\prime \prime}$ by providing a practical theorem for experimental investigations about the influence of tax amnesty on the risk of decision-making for tax evaders.

Suppose the original properties of a tax averse person be $B_{m}$, where $B_{m} \geq 0$, and the definitions of $y^{c}$ and $y^{e}$ be identical to those in Eq. (2). Consider the representative taxpayer, who participated in TAPs after the government proposed an amnesty, may not honestly report the whole amounts of evaded tax, thus committing a secondary tax evasion. The expected utility function is

$$
(1-\varepsilon) U\left(B_{m}+y^{c}\right)+\varepsilon U\left(B_{m}+y^{e}\right)-y^{\sigma} m v s \int \mathrm{d} F(s)
$$

Clearly, the indifference curve of tax evasion is in the bi-dimensional space of the probability of $y^{c}-y^{e}$; thus, it can be expressed as:

$$
(1-\varepsilon) U\left(B_{m}+y^{c}\right)+\varepsilon U\left(B_{m}+y^{e}\right)-y^{\sigma} m v s \int d F(s) \equiv U\left(W_{E}\right)
$$

Based on the implicit function theorem, we define the relationship of $y^{c}$ and $y^{e}$ as $y^{e}\left(y^{c}\right)$, in which Eq. (7) passes through $(0,0)$. A total differentiation of both sides of Eq. (7) generates the following:

$$
(1-\varepsilon) U^{\prime}\left(B_{m}+y^{c}\right)+\varepsilon U^{\prime}\left(B_{m}+y^{e}\right) y^{e^{\prime}}\left(y^{c}\right)=0
$$

Differentiating Eq. (8) generates the following:

$$
(1-\varepsilon) U^{\prime \prime}\left(B_{m}+y^{c}\right)+\varepsilon\left[U^{\prime \prime}\left(B_{m}+y^{e}\right)\left\{y^{e^{\prime}}\left(y^{c}\right)\right\}^{2}+U^{\prime}\left(B_{m}+y^{e}\right) y^{e^{\prime \prime}}\left(y^{c}\right)\right]=0
$$

Substituting $y^{c}=y^{e}=0$ into Eq. (8) generates $y^{e^{\prime}}(0)=-(1-\varepsilon) / \varepsilon$. Substituting $y^{c}=y^{e}=0$ into Eq. (9) generates

$$
(1-\varepsilon) U^{\prime \prime}\left(B_{m}\right)+\varepsilon\left\{U^{\prime \prime}\left(B_{m}\right) \frac{(1-\varepsilon)^{2}}{\varepsilon^{2}}+U^{\prime}\left(B_{m}\right) y^{e^{\prime \prime}}(0)\right\}=0
$$

which can be rearranged to form the following proposition: 


$$
y^{e^{\prime \prime}}(0)=\frac{(1-\varepsilon)}{\varepsilon^{2}}\left[\frac{-d \ln U^{\prime}\left(B_{m}\right)}{d B_{m}}\right],
$$

Proposition 3. If a tax evader's cardinal utility function is $U^{\prime \prime}\left(B_{m}\right) \geqq 0$, then $y^{e^{\leqq}}(0)>0$. The definition of Eq. (11) indicates that a greater Arrow-Pratt index of absolute risk aversion generates a greater curvature of the indifference curve near $(0,0)$ the bi-dimensional space of $y^{c} / y^{e}$. Therefore, let $\pi_{w}$ be the risk premium. If 'tax amnesty' is normal good, and $\pi_{w}\left(y^{e}\right) \geq \pi_{w}\left(y^{c}\right)$, then the corresponding gamble set size of joining TAPs, $\pi_{w}\left(y^{e}\right)$, is smaller than that of not joining such programs.

Under such conditions, joining TAPs is more advantageous than not. Figure 1 illustrates the representative tax evader's response to the TAP, after considering the representative evader, who participates in a TAP, may not honestly report the whole amounts of evaded tax, thus committing a secondary tax evasion. Clearly, this is a theoretical result which appears to be relatively robust; participating in TAPs yields relatively high levels of utility and is advantageous to tax averters.

In addition, based on Eqs $(7)$ and (11), we define $U^{\prime \prime \prime}\left(B_{m}\right)$ as continuous on $\left[B_{m}, W_{E}\right]$ with $0 \leq B_{m}<W_{E}$, and $\pi_{w}$, as defined above, denoting the risk premium. Intuitively, it implies that:

$$
U^{\prime \prime \prime}\left(W_{E}\right)-U^{\prime \prime \prime}\left(B_{m}\right) \geq 0, \forall W_{E}, \forall B_{m}
$$

Thus, if an amnesty is offered, the relationship between $W_{E}$ and $\pi$ can be expressed as follows:

$$
\frac{\mathrm{d} \pi_{w}}{\mathrm{~d} W_{E}}=\frac{U^{\prime}\left(y^{e}\right)-U^{\prime}\left(y^{c}\right)}{U^{\prime}\left(y^{e}\right)}<0, \forall y^{e}, \forall y^{c}
$$

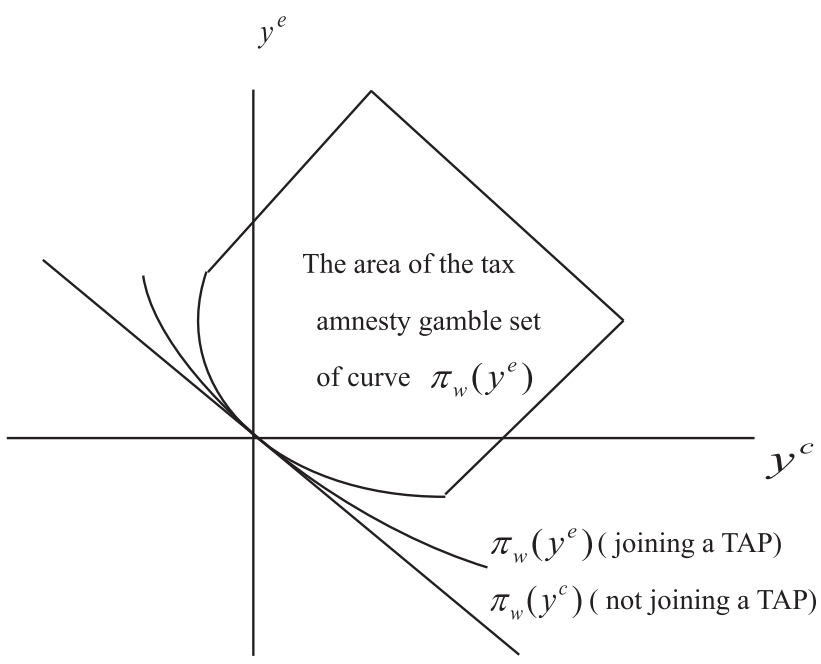

Figure 1. The gamble set of joining or not joining TAPs 
Eq. (13) implies that under the prevalence of tax amnesty, the greater the income, the lower the tax compliance is.

In this case, the representative tax evader reveals a decreasing absolute risk aversion (DARA). Thus, an increase in income leads to a decrease in tax compliance. This finding is seeking to supplement, but not supplant, the Arrow (1970) theory of risk aversion. We proved that the tax evasion behaviour of the representative taxpayers (the proportion of unreported income to real income), i.e. the degree of risk preference, will increase with the increase of representative taxpayers' income, which is in line with Slemrod - Yitzhaki's (2000) argument.

\subsection{The impact of tax amnesty on tax revenue}

Our analysis could be extended on the effect of tax amnesty on tax revenue. Stella (1991) indicated that a receipt of an additional tax revenue is typically unlikely to occur in the shortrun, because the tax amnesty plans may reduce the willingness of taxpayers to voluntarily file taxes, such plans may result in the long-term erosion of a country's tax base. However, contrary to Stella's assertion, our study determines that this statement may not be true in practice. According to various state-level tax amnesty plans in recent years implemented in the United States, almost all the states experienced a short-term increase in fiscal revenue because the tax evaders paid overdue taxes or negotiated fines. ${ }^{5}$ The tax amnesty plans exhibit a positive effect on tax revenue for the US state governments.

\subsection{Tax revenue without implementing tax amnesty}

To examine the impact of tax amnesty on tax revenue, Andreoni (1991) argued that tax revenue increase as a result of tax amnesty plans is influenced by the amount of taxes evaded before their participation in the tax amnesty plans. However, he ignored the impact of the assessment period on tax amnesty and tax revenue. Therefore, in this section, the general settings employed by the previous literature are utilised to investigate the influence of tax amnesty plans and the assessment period on tax revenue.

Suppose that the assessment period in which the government implemented a tax amnesty plan is defined as $J$; an exogenous variable, $R^{e}$, signifying the estimated total tax revenue during the assessment period after implementation of a tax amnesty plan; the estimated total tax revenue without implementing the tax amnesty plan is defined as $S^{e} ; 0<t<T$, marking the period in which the tax amnesty plan was implemented; $T$ represents the last day of the assessment period; and $\lambda$ and $\mu$ are the variables of the indicator function that display the relationship between time and tax revenue. The expected tax revenue without implementing the tax amnesty plan $S^{e}$ changes as time $t$ changes. The exponential function to define this relationship can be expressed as follows:

\footnotetext{
${ }^{5}$ For example, the Government of Connecticut experienced an increase in tax revenue of approximately US\$175-180 million after the tax amnesty plan was implemented in 2013. Other examples: 2005 California US\$683 million, 2009 New Jersey US\$661 million, Louisiana US\$439 million, 2010 Florida US\$160 million (this tax amnesty plan lasted only 90 days) and 2013 Nebraska US\$8.98 million. http:/www.governing.com/columns/assessments/gov-tax-now-pay-later. html.
} 


$$
S^{e}(t)=e^{-\lambda t+\mu}
$$

Eq. (14) indicates the changes in the relationship between time and tax revenue for the various assessment periods when no tax amnesty plan was implemented by the government.

Eq. (15) was the differential equation for the tax revenue collected.

$$
\frac{d S^{e}}{d t}=-\lambda S^{e}
$$

\subsection{Short-term effect of tax amnesty on tax revenue}

Assuming that a certain percentage of tax evaders would participate in the tax amnesty plan during the assessment period, the changes in tax revenue over time would be directly proportional to

$$
\frac{\gamma J\left(R^{e}-S^{e}\right)}{R^{e}}
$$

This study demonstrated that during the initial assessment period of the tax amnesty plan the tax revenue drastically increases. However, as the assessment period gradually approaches to the final day of the assessment period, the probability that tax evaders are exempted from penalties and successfully evade taxes increases. Hence, tax revenue received by the government gradually declined and ultimately converged on a fixed value (some examples are Arindam et al.1995; Luitel - Mahar 2013; Luitel - Sobel 2007).

Proposition 4. During the initial period in which the government implements a tax amnesty plan, tax revenue drastically increases. However, as the assessment period gradually approached the final day of the assessment period, the tax revenue stably declined and ultimately converged to a fixed value.

Proof: See Appendix 2 for details.

Based on the above deduction and compared with the non-implementation of the tax amnesty plan, we show that the tax amnesty plan not only affects the current tax revenue of a government but also causes a declining increase in the tax revenue of a country after the current period. Therefore, the tax base, upon which the tax amnesty operates, is some historical and cumulative moving sum far larger than one year's tax collections.

In addition to Arindam et al. (1995); Luitel - Mahar (2013); Luitel - Sobel (2007) are in line with our above arguments. Laffer (2003) takes the United States for instance, a federal, state and local tax amnesty would add some $\$ 50$ billion in the first year and $\$ 25$ billion over the coming 10 years. Obviously, the governors perceive tax amnesties as another revenue source rather than a tax increase alternative, Laffer's argument is consistent with our proposition.

\section{PARETO IMPROVING AND TAX AMNESTY}

\subsection{The higher the income of the representative tax evader, the higher the tax amnesty penalty he/she is willing to pay}

Since the publication of Guesnerie (1977), the issue of Pareto improving tax reform has attracted attention. Pareto improvement usually leads to social welfare improvement, but social welfare improvement is not necessarily Pareto improvement. However, Ahmad - Stern (1984) proved 
that there is a close relationship between feasible Pareto improvement and social welfare function.

The Luitel - Tosun's paper (2014) regards joining TAPs as Pareto improvement because it benefits tax evaders without damaging other parties. However, the implementation of the tax amnesty scheme by the government would reduce the tax compliance rate of honest taxpayers, which was contrary to the tax level and vertical fairness. Yet, Bose - Jetter (2012) show that a successful amnesty can be welfare enhancing, even if it has a negative impact on revenue generation.

In this section, all mathematical symbols are defined the same as before in this article. Assuming that under the random check mechanism with audit rate $p$, a representative taxpayer chooses to declare $(1-v) y^{\sigma}$ to maximize his/her expected utility level as follows:

$$
\underset{(1-v) y^{\sigma}}{\operatorname{Max} E U}=(1-p) V(A)+p V(B)
$$

where $p$ is the probability of being caught evading taxes; and $(1-p)$ is the probability of a successful escape, assumepis independent of the reported income and $A=y^{\sigma}-T\left((1-v) y^{\sigma}\right)$, $B=y^{\sigma}-T\left((1-v) y^{\sigma}\right)-\tau \times\left(T\left(y^{\sigma}\right)-T(1-v) y^{\sigma}\right), A$ and $B$ represent the income level of taxpayers under non-auditing and auditing conditions respectively.

$\mathrm{V}(\cdot)$ satisfies the expected utility axiom of von Neumann-Morgenstern (Allingham Sandmo 1972, Yitzhaki 1974). The optimal solution obtained by Eq. (17) is $J(y)$, where $J(y)=$ $(1-\mathrm{v}) y$, and the indirect expected utility function of taxpayers can be obtained by introducing $J$ (y) into Eq. (17). The gross expected tax revenue received by tax authorities from the representative taxpayer is ER (y), which is expressed in Eq. (18):

$$
\mathrm{ER}\left(y^{\sigma}\right)=\mathrm{T}\left((1-v) y^{\sigma}\right)+\mathrm{p} \tau\left(\mathrm{T}\left(y^{\sigma}\right)-\mathrm{T}\left((1-v) y^{\sigma}\right)\right.
$$

After a tax evasion, a representative tax evader takes part in the tax amnesty plan and declares his/her unreported tax voluntarily, the maximum penalty that he/she is willing to pay after participating in the tax amnesty scheme is denoted as $F\left(y^{\sigma}\right)$, where $F\left(y^{\sigma}\right)$ satisfies the following Eq. (19):

$$
\mathrm{V}\left(\mathrm{y}^{\sigma}-\mathrm{F}\left(\mathrm{y}^{\sigma}\right)\right)=\mathrm{EU}\left(\mathrm{y}^{\sigma}\right)
$$

Eq. (19) shows that when the threshold of tax amnesty penalty required by tax authorities is not higher than the highest price that taxpayers are willing to pay, i.e. $\overline{\mathrm{F}} \leq \mathrm{F}\left(\mathrm{y}^{\sigma}\right)$, the taxpayer will choose to pay $\overline{\mathrm{F}}$ to avoid being checked. Conversely, when the threshold of tax amnesty fine required by tax authorities is higher than the highest price that tax evaders are willing to pay, it is representative. Taxpayers will choose not to participate in the tax amnesty plan and prefer to face the random checking mechanism. To ensure that there is an internal solution, the model assumes that $T^{\prime} \tau^{\prime}>1$, and the static results of $\mathrm{F}\left(\mathrm{y}^{\sigma}\right)$ can be further inferred from Eqs (19) and (20) proves that the taxpayers with higher income are willing to pay the highest price in order to avoid the risk of being checked.

\subsection{Pareto improvement under government TAP}

Any function that takes the indirect utility function of all members as variable, $W\left(v^{1}, \ldots, v^{n}\right)$, is called social welfare function. We set $y_{n}^{\sigma}$ as the real income of the $N$ members of a society. If the social function has the property of $\partial W / \partial y_{n}^{\sigma} \geq 0$ for all members, where $n \in N$, we regard the government as another member of the society other than member $n$, if the revenue from tax 
amnesty penalties are not less than the expected tax revenue, then the Pareto social welfare improvement can be achieved.

$$
\begin{aligned}
& \operatorname{Max} W\left(\underset{(1-v) y^{\sigma}}{\left(v^{1}, \ldots, v^{n}\right)}\right. \\
& \text { subject to } R\left(\sum_{n=1}^{N}\left(1-v_{n}\right) y_{n}^{\sigma}\right)=\text { constant }
\end{aligned}
$$

where $R$ is tax function.

Corollary 1. From Eq.(17) to Eq.(20), we show that if a representative taxpayer is willing to pay tax amnesty penalty, $\overline{\mathrm{F}} \leq \mathrm{F}\left(y^{\sigma}\right)$, no less than the expected tax revenue of the government, $\operatorname{ER}\left(\mathrm{y}^{\sigma}\right)$, then the tax amnesty penalties imposed by the government on the taxpayer will increase the government revenue without reducing the welfare of other taxpayers, so as $\mathrm{dV}^{\mathrm{n}}=0, \mathrm{dR}>0$, at this time, the whole society reached a Pareto improvement.

\section{CONCLUSIONS AND DISCUSSION}

The purpose of our research was to study the possibility that tax evaders engage in repeated tax evasion after participating in the tax amnesty plan. Our research contributed to the literature on tax amnesties in seven ways:

- The influence of the erosion rate of the tax base due to a tax evader's option to join a tax amnesty plan on the second order condition of the subjective expected utility of the tax evader is characterised by a strictly concave function.

- If $\tau q \theta \geq \chi$, the influence of the proportion of back duty payments (recovered from tax evaders who voluntarily paid the negotiated penalties and overdue taxes that were not discovered during the previous periods) on the second-order condition of the subjective expected utility of tax evaders exhibites a strictly concave function. However, if $\tau q \theta<\chi$, then the representative taxpayer may not fully declare his/her tax evasion after participating in the tax amnesty, resulting in a second tax evasion.

- In comparison with the tax evaders who did not participate in the tax amnesty plan, those who participated exhibited higher differentiable von Neumann-Morgenstern cardinal utility function. In other words, it shows that, provided there are no changes in the penalty rate, and thus, the probability of being caught evading taxes, even if tax evaders who participated in TAPs may not honestly report the whole amounts of evaded tax, thus committing a secondary tax evasion. Nonetheless, this result reveals that the tax evaders participated in TAPs yield relatively high levels of von Neumann-Morgenstern cardinal utility, and it is always beneficial to the tax evaders.

- The results of this study support the puzzle of compliance philosophy proposed by Diego Luca (2011), demonstrating the reason that tax evaders are willing to participate in tax amnesty plans despite the probability of the exogenous variables "penalty rate" and "probability of tax evasion activities being discovered" being low. 
- The willingness of the tax evaders to actively participate in the tax amnesty plans after a tax evasion decreases as the wealth of the tax evaders increases, indicating that the tax evaders' utility function features decreased absolute risk aversion (DARA) (a robust assumption) and that risky assets subject to tax amnesty are normal goods (i.e. the elasticity obtained from the absolute risk aversion function is greater than the robust assumption of zero).

- During the initial assessment period of the tax amnesty plan, tax revenue drastically increased. However, because the tax payers are exempted from fines and are not required to pay overdue taxes when the assessment period ends, tax revenue stably declined and ultimately converged to a fixed value.

- If taxpayers are willing to pay tax amnesty penalties which are larger than the expected tax revenue of the government, then the tax amnesty penalties imposed by the government on taxpayers increase government revenue without reducing the welfare of other taxpayers. At this time, the whole society reaches a Pareto improvement.

Finally, contrary to Ueng - Yang (2001), we argue that it is not advisable for a tax evader to pay the penalty to the government after a tax evasion in exchange for the fact that the tax evaders will no longer accept the examination of tax authorities for their undisclosed income before they participate in the tax amnesty scheme. This is also the reason why we suggest that the tax evaders who fail to pay their tax evasion honestly after participating in the tax amnesty plan must be punished more severely when they are found to have evaded the second tax by the government.

\section{ACKNOWLEDGEMENTS}

We are especially grateful to the referees of Acta Oeconomica for their comments, as well as to all members of the Guangdong Ocean University Cunjin College (China) and Beibu Gulf Economic Centre (China) for their continuous aid and support during the completion of this research.

\section{REFERENCES}

Ahmad, S. E. - Stern, N. H. (1984): The Theory of Tax Reform and Indian Indirect Taxes. Journal of Public Economics, 25(3): 259-298.

Allingham, M. G. - Sandmo, A. (1972): Income Tax Evasion: A Theoretical Analysis. Journal of Public Economics, 1(3-4): 323-338.

Alm, J. - Mckee, M. - Beck, W. (1990): Amazing Grace Tax Amnesties and Compliance. National Tax Journal, 43(1): 23-37.

Alm, J. - Beck, W. (1990): Tax Amnesties and Tax Revenues. Public Finance Quarterly, 18(4): 433-453. Andreoni, J. (1991): The Desirability of a Permanent Tax Amnesty. Journal of Public Economics, 45(2): 143-159.

Arindam, D. G. - Radhika, L. - Dilip, M. (1995): Income Tax Compliance in India: An Empirical Analysis. World Development, 23(12): 2051-2064.

Arrow, K. J. (1965): Aspects of the Theory of Risk-Bearing. Helsinki: Yrjö Jahnsson Lectures.

Arrow, K. J. (1970): Essays in the Theory of Risking-Bearing. Amsterdam: North-Holland. 
Bose, P. - Jetter, M. (2012): Liberalization and Tax Amnesty in a Developing Economy. Economic Modelling, 29(3): 761-765.

Cyert, R. M. - DeGroot, M. H. (1987): Bayesian Analysis and Uncertainty in Economic Theory. N. Y.: Rowman \& Littlefield Press.

Das Gupta, A. - Lahiri, R. - Mookherjee, D. (1995): Income Tax Compliance in India: An Empirical Analysis. World Development, 23(12): 2051-2064.

Das Gupta, A. - Mookherjee, D. (1995): Tax Amnesties in India: An Empirical Evaluation. IRIS-India Working Paper, No. 4.

Diego, L. - Luca, Z. (2011): Happiness and Tax Morale: An Empirical Analysis. Journal of Economic Behavior and Organization, 80: 223-243.

Fisher, R. C. - Goddeeris, J. H. - Young, J. C. (1989): Participation in Tax Amnesties: The Individual Income Tax. National Tax Journal, 42(1): 15-27.

Guesnerie, R. (1977): On the Direction of Tax Reform. Journal of Public Economics, 7: 179-202.

Hanson, D. L. - Menezes, C. F. (1971): On a Neglected Aspect of the Theory of Risk Aversion. Western Economic Journal, 2: 211-217.

Laborda, J. L. - Rodrigo, F. (2003): Tax Amnesties and Income Tax Compliance: The Case of Spain. Fiscal Studies, 24(1): 73-96.

Laffer, A. B. (2003): State of the Economy: Tax Amnesty - A Win-Win for Everybody. Wall Street Journal, 23June.

Leonard, H. B. - Zeckhauser, R. J. (1987): Amnesty, Enforcement, and Tax Policy. In: Summers, L. H. (eds): Tax Policy and the Economy, Vol. 1, pp. 55-85, NBER - MIT Press.

Lubian, D. - Zarri, L. (2011): Happiness and Tax Morale: An Empirical Analysis. Journal of Economic Behavior and Organization, 80(1): 223-243.

Luitel, H. S. - Mahar, G. (2013): Is a Tax Amnesty a Good Fiscal Policy? A Review of State Experience in the USA. Economics Bulletin, 33(1): 1-7.

Luitel, H. S. - Sobel, R. S. (2007): The Revenue Impact of Repeated Tax Amnesties. Public Budgeting and Finance, 27(3): 19-38.

Luitel, H. S. - Tosun, M. S. (2014): A Reexamination of State Fiscal Health and Safety Engagement. International Tax and Public Finance, 21(5): 874-893.

Macho-Stadler, I. - Olivella, P. - Pérez-Castrillo, D. (1999): Tax Amnesties in a Dynamic Model of Tax Evasion. Journal of Public Economic Theory, 1(4): 439-463.

Marceau, N. - Mongrain, S. (2000): Amnesties and Co-Operation. International Tax and Public Finance, 7(3): 259-273.

Malik, A. S. - Schwab, R. M. (1991): The Economics of Tax Amnesties. Journal of Public Economics, 46(1): $29-49$.

Olivella, P. (1996): Tax Amnesties and Tax Evasion Inertia. Public Finance/Finances Publiques, 51(4): 572589.

Pratt, J. W. (1964): Risk Aversion in the Small and the Large. Econometrica, 32(1): 122-136.

Slemrod, J. - Yitzhaki, S. (2000): Tax Avoidance, Evasion, and Administration. National Bureau of Economic Research, Working Paper, No. 7473.

Slemrod, J. - Yitzhaki, S. (2002): Tax Avoidance, Evasion, and Administration. In: Auerbach, A. - Feldstein, M. (eds): Handbook of Public Economics, pp. 1423-1470, Amsterdam: Elsevier Science, North-Holland. Stella, P. (1991): An Economic Analysis of Tax Amnesties. Journal of Public Economics, 46(3): 383-400.

Torgler, B. - Schaltegger, C. A. (2005): Tax Amnesties and Political Participation. Public Finance Review, 33(3): 403-431. 
Uchitelle, E. (1989): The Effectiveness of TAPs in Selected Countries. Federal Reserve Bank of New York Quarterly Review,14(3): 48-53.

Ueng, K. L. G. - Yang, C. C. (2001): Plea Bargaining with the IRS: Extensions and Further Results. Journal of Public Economics, 81(1): 83-98.

von Neumann, J. - Morgenstern, O. (1944): Theory of Games and Economic Behavior. Princeton: Princeton University Press.

Yitzhaki, S. (1974): A Note on Income Tax Evasion: A Theoretical Analysis. Journal of Public Economics, 3(2): 201-202.

\section{APPENDIX 1}

In Proposition 1, consider a risk-neutral agent and the objective of a tax evader who has not been found guilty of a tax evasion prior to the current period is to pursue the minimal individual cost of joining a TAP. Let $q$ be a representative tax evader who actively participates in the tax amnesty plan but fails to fully declare the evaded tax, and the probability of being found by the government; the cost of a tax evader can be expressed as:

$$
\Delta C=\operatorname{Min}_{\kappa \in[0,1]}[m \times \chi \times \kappa+q \theta \times(1-\kappa) \times m \times \tau] \times y^{\sigma} \times v
$$

where $\theta$ denotes the probability of being caught hiding incomes through any type of government inspection. Adopt $\kappa$, as the proportion of back duty payments of a tax evader who joins a TAP, to determine the first-order optimal control condition of the aforementioned equation: $\theta^{A}=\frac{\chi}{\tau \times q}$; the optimal strategy for a tax evader regarding joining a TAP can be expressed as: ${ }^{6}$

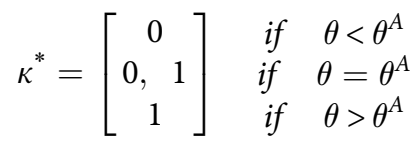

This deduction proves that only the evaders who meet the condition of $\theta^{A}<\theta$ choose to join a TAP. Thus, a tax evader with the condition of $\theta^{A}>\theta_{t-1}=\theta^{*}, \theta \in\left[0, \theta^{A}\right]$ does not join such program. The number of tax evaders who have not been caught committing a tax evasion before the current period $(\mathrm{t})$ can be expressed using the probability density function $\left(1-q^{*}\right) \times \widehat{\theta}$. Thus, $\left(1-q^{*}\right) \times \widehat{\theta}=\min \left\{\theta^{*} ; \frac{\varpi^{\circ}}{q_{t}}\right\}$, where $\varpi^{\circ}=\frac{\chi}{\tau}$ and $\varpi^{\circ}$ denotes the ratio of $\chi$ (the amnesty penalty rate of each dollar evaded) to $\tau$ (the penalty rate, which is greater than the marginal tax rate $m$ ) that must be paid by a tax evader who did not join a TAP and is subsequently discovered by tax authorities. Therefore, the premise for an amnesty program to be effective is $\frac{\varpi^{\circ}}{q_{t}}<\theta_{t}^{*}$. ${ }^{6}$ If tax penalties are based on the evaded incomes of a tax averter, then $\Delta C=\underset{\kappa \in[0,1]}{\operatorname{Min}}\left[\beta \times \sigma+q_{t} \times \theta \times(1-\sigma) \times \tau\right] \times$
$y \times v, \theta^{A}=\frac{\chi}{\tau \times q_{t}}$ 


\section{APPENDIX 2}

Based on Eqs (14) and (15), the differential equation is expressed:

$$
\frac{d S^{e}}{\mathrm{dt}}=-\lambda \times S^{e}+\gamma \times J \times \frac{R^{e}-S^{e}}{R^{e}}
$$

Further computations produce a nonhomogeneous equation:

$$
\frac{d S^{e}}{d t}=-\left(\lambda+\gamma \times \frac{J}{R^{e}}\right) \times S^{e}+J \times \gamma
$$

The homogeneous equation corresponding to the nonhomogeneous equation (A.2.2), is as follows:

$$
\frac{d S^{e}}{d t}=-\left(\lambda+\gamma \times \frac{J}{R^{e}}\right) \times S^{e}
$$

Using the separation of variables method, the following equation is obtained:

$$
\int \frac{d S^{e}}{S^{e}}=-\left(\lambda+\gamma \times \frac{J}{R^{e}}\right) \times \int \mathrm{d} t
$$

By using the integrals from both sides of the equation, the following equation is formulated:

$$
\ln \left|S^{e}\right|=-\left(\lambda+\gamma \times \frac{J}{R^{e}}\right) \times t+C
$$

Solving this equation produces the result: $S^{e}= \pm e^{-\left(\lambda+\gamma \times \frac{I}{R^{e}}\right) \times t+C}$

By setting the constant $C= \pm e^{C}$ and substituting this constant into the aforementioned equation, the general solution for the homogeneous Eq. (A.2.3) is obtained:

$$
S^{e}=c \times e^{-\left(\lambda+\gamma \times \frac{I}{R^{e}}\right) \times t}
$$

The general solution Eq. (A.2.6) of the homogeneous equation is modified and the constant $c$ is changed to the constant for time $c(t)$ to satisfy the nonhomogeneous Eq. (A.2.2) and obtain the hypothetical solution for the nonhomogeneous equation:

$$
S^{e}(t)=c(t) \times e^{-\left(\lambda+\gamma \times \frac{J}{R^{e}}\right) \times t}
$$

Because the solution of Eq. (A.2.7) must satisfy the differential Eq. (A.2.2), the aforementioned equation is substituted into the equation and the derivative is calculated to produce the following equation:

$$
\begin{aligned}
& \frac{d c(t)}{d t} \times e^{-\left(\lambda+\gamma \times \frac{I}{R^{e}}\right) \times t}+c(t) \times\left[-\left(\lambda+\gamma \times \frac{J}{R^{e}}\right) \times e^{-\left(\lambda+\gamma \times \frac{I}{R^{e}}\right) \times t}\right] \\
& =-\left(\lambda+\gamma \times \frac{J}{R^{e}}\right) \times c(t) \times e^{-\left(\lambda+\gamma \times \frac{I}{R^{e}}\right) \times t}+\gamma \times J
\end{aligned}
$$

The following equation is derived by rearranging the equations: 


$$
\frac{d c(t)}{d t}=\gamma \times J \times e^{-\left(\lambda+\gamma \times \frac{J}{R^{e}}\right) \times t}
$$

By setting $\beta=\lambda+\gamma \times \frac{J}{R^{e}}$ and calculating the integral, the following equation is obtained:

$$
c(t)=\gamma \times J \times \int e^{\beta t} \mathrm{~d} t=\gamma \times J \times \frac{e^{\beta t}}{\beta}+c^{\prime}
$$

Therefore, the general solution for the nonhomogeneous equation is expressed as follows:

$$
S^{e}(t)=\left(\gamma \times J \times \frac{e^{\beta t}}{\beta}+c^{\prime}\right) \times e^{-\beta t}=\frac{\gamma \times J}{\beta}+c^{\prime} \times e^{-\beta t}
$$

The initial value of the actual tax revenue is set as $S(0)=S_{0}$ and substituted into Eq. (A.2.11) to produce the following result:

$$
\begin{gathered}
S(0)=S_{0}=\frac{\gamma \times J}{\beta}+c^{\prime} \times e^{-\beta \times 0} \\
\therefore c^{\prime}=S_{0}-\frac{\gamma \times J}{\beta}
\end{gathered}
$$

Therefore, the expected cumulative tax revenue for assessment period $0<t<T$ is as follows:

$$
S^{e}(t)=\frac{\gamma \times J}{\beta}+\left[S_{0}-\frac{\gamma \times J}{\beta}\right] \times e^{-\beta t}
$$

Equation (A.2.13) indicates that during the initial assessment period of the tax amnesty plan, tax revenue drastically increases. However, as the final day of the assessment period approaches, tax revenue stably declines and ultimately converges to a fixed value. 